\title{
A Study on the Administration of Surfactant and its Outcome in Term and Late Preterm Infants with Meconium Aspiration Syndrome
}

\author{
Dr. Banasree Roy ${ }^{1}$, Dr. Sandip Sen ${ }^{2 *}$, Dr. Suhit Banerjee ${ }^{3}$, Dr. Dhrubojyoti Halder ${ }^{4}$
}

${ }^{1}$ Assistant Professor, ${ }^{2}$ Associate Professor, ${ }^{3}$ Junior Resident, ${ }^{4}$ Senior Resident, Dr. B.C.Roy Postgraduate Institute of Paediatric Sciences, 111Narkeldanga Main Road, Kolkata, India

DOI: $\frac{10.36348 / \mathrm{sjmps} .2019 . \mathrm{v} 05 \mathrm{i} 12.014}{\text { *Corresponding author: } \text { Dr. Sandip Sen }}$

| Received: 08.12.2019 | Accepted: 22.12.2019 | Published: 27.12.2019

Abstract

Objective: To evaluate the effect of surfactant administration in the treatment of term and late preterm neonates with meconium aspiration syndrome (MAS) in relation to outcome in terms of need for ventilation and mortality. Methodology: This study is a prospective observational study of late preterm>34 - 36 6/7 weeks and term neonates with moderate and severe meconium aspiration syndrome (MAS) admitted in Dr B C Roy Postgraduate Institute of Pediatric Sciences, Kolkata. Study was done by application of surfactant within 24 hrs and 25 to 48 hrs of birth. Requirement for supplemental oxygen and ventilation were recorded in predesigned proformas. Results: The outcome in terms of death between within $24 \mathrm{hrs}$ and 25-48 hrs of birth application of surfactant in MAS is mortality in the former was 3/20(15\%) as compared to $2 / 10(20 \%)$ in the latter though it was not statistically significant $(\mathrm{p}=0.301)$. Mean duration of ventilation, $(\mathrm{p}=0.026)$ supplemental oxygen requirement $(\mathrm{p}=0.039)$ and the length of hospital stay $(\mathrm{p}=0.045)$ were significantly lower in those who received surfactant within $24 \mathrm{hrs}$ of birth in comparison to who received within 25-48 hrs of birth.(alpha value for $\mathrm{p}=0.05)$. Conclusion: Surfactant in a form of bolus therapy within 24 hrs of birth has no role in decreasing the percentage of mortality or morbidity in MAS but however has shown benefit in terms of decreasing the mean duration of ventilation, $\mathrm{O}_{2}$ requirement and hospitalization.

Keywords: Meconium aspiration syndrome, Surfactant, Mechanical ventilation, Supplemental oxygen, Neonates.

Copyright @ 2019: This is an open-access article distributed under the terms of the Creative Commons Attribution license which permits unrestricted use, distribution, and reproduction in any medium for non-commercial use (NonCommercial, or CC-BY-NC) provided the original author and source are credited.

\section{INTRODUCTION}

Meconium stained amniotic fluid is found in $10-15 \%$ of births and usually occurs in term or postterm infants. Meconium stained infants require resuscitation at birth [1].

Either in utero or more often with the first breath, thick, particulate meconium is aspirated into the lungs. The resulting small airway obstruction may produce respiratory distress within the first few hours, with tachypnea, retractions, grunting and cyanosis. If meconium is not removed from the trachea after delivery, with the onset of respiration it migrates from the central airways to the periphery of the lung. Initially particles of meconium produce mechanical obstruction of the small airways that results in hyperinflation with patchy atelectasis. Later small airway obstruction is the result of chemical pneumonitis and interstitial edema. During this later stage hyperinflation persists and areas of atelectasis become more extensive. Partial obstruction of some airways may lead to pneumothorax or pneumomediastinum or both [2].
In 1990, Moses and colleagues discovered that surfactant inactivation is related to both the consistency of the meconium and the concentration of the surfactant itself. This information suggested that neonates who aspirated thick meconium might benefit from exogenous surfactant [3]. Surfactant improved oxygenation, resolved persistent pulmonary hypertension, decrease air leaks, duration of ventilation [4]. Deficiency of surfactant or surfactant dysfunction is contributing factor to respiratory failure in MAS [5].

Three randomized controlled trials confirm some benefits of the administration of several boluses of a natural surfactant in the treatment of MAS. Although overall mortality was no difference between the treatment group and the placebo group in each of these trials, the administration of several doses of a natural preparation was found to improve oxygenation in all three, to reduce the need for ECMO in two, and to reduce the risk of pneumothorax in one [6]. Surfactant therapy is one of the newer promising modes of 
therapeutic interventions in babies with severe MAS [7$10]$.

Current evidence would support the use of bolus surfactant therapy on a case by case basis in nurseries with a relatively high mortality associated with MAS, or the lack of availability of other forms of respiratory support such as HFV or NO [11].

\section{METHODOLOGY}

This study is an observational study of late preterm and term neonates with severe MAS admitted in Dr B C Roy PGIPS, Kolkata. Ethical clearance was obtained from Institutional Ethics Committee. Informed consent was obtained before enrollment. Time period of this study was from January 2017 to December 2017(one year). 30 patients was included in this study. Clinical history was taken and relevant clinical examination was done. Study was done by application of surfactant within $24 \mathrm{hrs}$ and $25-48 \mathrm{hrs}$ of birth. Findings of investigations including CBC, CRP, ABG, urea, creatinine and $\mathrm{X}$-ray and echocardiography were noted. Duration of Oxygen therapy and duration of mechanical ventilation were recorded.
Late preterm (34-36 6/7 weeks) and term neonates with moderate and severe MAS were included in this study. Neonates <34 weeks, neonates $>34$ weeks with mild MAS and/or MAS with CHD were excluded.

All recorded data are analyzed using SPSS v20.0 and transferred onto an Excel database. Standard statistical methods were used and the data was analyzed thoroughly to draw the appropriate conclusion. The alpha value of $\mathrm{p}$ was taken to be 0.05 . Values below it were considered significant.

\section{RESULTS}

Regarding gestational age, there is no statistically significant difference between administration of surfactant within $24 \mathrm{hrs}$ and $25-48 \mathrm{hrs}$ of birth. ( $p=0.760$, Chi-square test, value $=0.093$, degree of freedom is 1 ).

Regarding the birth weight, there is no statistically significant difference between administration of surfactant within $24 \mathrm{hrs}$ and 25-48 hrs of birth. $(\mathrm{p}=1.00$, Chi-square test,value $=1.00$, degree of freedom is 1 )

Table-1: Administration of Surfactant in relation to Gestational Age and Birth Wt

\begin{tabular}{|l|l|l|l|l|l|l|l|}
\hline & & Gestational age & & Total & Birth weight & & Total \\
\hline & & $\mathbf{3 7} \mathbf{w k s}$ & $\mathbf{3 5 - 3 6} \mathbf{6} / \mathbf{7} \mathbf{~ w s}$ & & $\mathbf{> = 2 . 5} \mathbf{~ k g}$ & $<\mathbf{2 . 5} \mathbf{~ k g}$ & \\
\hline $\begin{array}{l}\text { Surfactant } \\
\text { administration }\end{array}$ & Upto 24hrs & 15 & 5 & 20 & 18 & 2 & 20 \\
\hline & & & & & & & \\
\hline Total & $25-48 \mathrm{hrs}$ & 8 & 2 & 10 & 9 & 1 & 10 \\
\hline
\end{tabular}

Regarding the duration of $\mathrm{O}_{2}$ supplementation, $\mathrm{P}=0.039$ (Chi-square test, value $=6.477$, degree of freedom 2) and hence the statistically significant difference suggesting that those MAS babies received surfactant within $24 \mathrm{hrs}$ of delivery had needed the shorter duration of $\mathrm{O}_{2}$ supplementation that those received within 25-48 hrs of delivery.
Regarding the duration of ventilation, $\mathrm{P}=$ 0.026 (chi-square test, value $=7.274$, degree of freedom 2 ) and hence the statistically significant difference suggesting that those MAS babies received surfactant within $24 \mathrm{hrs}$ of delivery had shorter duration of ventilation that those received within $25-48$ hrs of delivery.

Table-2: Duration of Oxygen Supplementation and Ventilation in relation to the time of Surfactant Administration

\begin{tabular}{|c|c|c|c|c|c|c|c|c|}
\hline & & \multicolumn{3}{|c|}{ Duration of $\mathrm{O}_{2}$ therapy } & \multirow[t]{2}{*}{ IMV req. } & \multicolumn{3}{|c|}{ Duration of Ventilation } \\
\hline Days & & $1-7$ & $8-14$ & $15-21$ & & $1-5$ & $6-10$ & $11-15$ \\
\hline Surfactant administration & $<24 \mathrm{~h}$ & 15 & 5 & 0 & 17 & 11 & 6 & 0 \\
\hline & $25-48 \mathrm{~h}$ & 3 & 6 & 1 & 8 & 3 & 2 & 3 \\
\hline Total & & 18 & 11 & 1 & 25 & 14 & 8 & 3 \\
\hline
\end{tabular}

Regarding complications,in case of emphysema $\mathrm{P}=0.150$ ( Chi-square test, value $=2.069$, degree of freedom 1 ) and in case of PPHN $\mathrm{P}=0.760$ (Chi-square test, value $=0.093$, degree of freedom 1 ). So, in both the cases there is no statistically significant difference between administration of surfactant within $24 \mathrm{hrs}$ and 25-48 hrs of birth.

As per the above data, no pf death is 3 vs 2 and discharge $17 / 8$ ( $\mathrm{p}$ value is 0.301 , chi-square test, value $=1.071$ degree of freedom 1 ) with no statistically difference between the outcome in term of discharge/death between $24 \mathrm{hrs}$ and 25-48 hrs of birth application of surfactant in MAS. 
Table-3: Complications and outcome in relation to surfactant administration

\begin{tabular}{|c|c|c|c|c|c|c|c|}
\hline & & Emphysema & & PPHN & & Outcome & \\
\hline & & No & Yes & No & Yes & Discharge & Death \\
\hline Surfactant administer & Upto $24 \mathrm{hrs}$ & 20 & 0 & 15 & 5 & 17 & 3 \\
\hline & $25-48 \mathrm{hrs}$ & 9 & 1 & 8 & 2 & 8 & 2 \\
\hline Total & & 29 & 1 & 23 & 7 & 25 & 5 \\
\hline
\end{tabular}

\section{DISCUSSION}

Meconium aspiration syndrome (MAS) is a common problem that most pediatricians will encounter in the delivery room and normal newborn nursery. MAS are one of the important causes of mortality and morbidity in the neonates in our country. As secondary surfactant deficiency and inactivation is one of the important pathophysiological mechanism responsible for the MAS, our study focuses on the efficacy of exogenous surfactant administered in the form of bolus therapy according to the age of presentation (Within 24 hrs. of birth and from 25-48 hrs. of birth).

Table-4: Comparison of sample size,type of study and subjects between various studies

\begin{tabular}{|l|l|l|l|l|l|l|}
\hline & Present & $\begin{array}{l}\text { Findlay } \text { et al. } \\
{[\mathbf{1 0}]}\end{array}$ & $\begin{array}{l}\text { Lotze } \text { et al. } \\
{[\mathbf{1 4}]}\end{array}$ & $\begin{array}{l}\text { Maturana } \\
\text { et al. }[\mathbf{1 5}]\end{array}$ & $\begin{array}{l}\text { Wiswel } \text { et al. } \\
{[\mathbf{1 2}]}\end{array}$ & $\begin{array}{l}\text { Bandiya } \text { et al. } \\
{[\mathbf{1 3}]}\end{array}$ \\
\hline No of Cases & 30 & 20 & 87 & 28 & 15 & 30 \\
\hline Control & Not applicable & 20 & 81 & 29 & 7 & 30 \\
\hline Type of Study & Observational & RCT & RCT & RCT & RCT & RCT \\
\hline Gestational age in weeks & \multirow{2}{*}{$>34$} & $>37$ & $>36$ & $>37$ & $>35$ & $>37$ \\
\hline
\end{tabular}

Sample size: No of cases compared to various studies is close to Findlay et al. Maturana et al. Bandiya et al. studies

Gestational age: All cases aged >34 weeks, minimum $=35$ weeks, maximum $=42$ weeks, with no statistical significance comparable to Wiswell et al. study.

Surfactant administration: As multiple bolus therapy [Survanta] $4 \mathrm{ml} / \mathrm{kg}$ given through ET tube in small aliquots of $2 \mathrm{ml}$ in the supine position with use of handbag ventilation after administration to increase the positive inspiratory pressure, sufficient care taken to prevent complications during administration. In comparison of surfactant administration between various studies, we can see in Chinese collaborative group, Findley et al. [10], Lotae et al.[14], Maturana et al. [15] Survanta type of surfactant was administered as multiple doses of bolus infusion like the same done in our study. But in Wiswell et al. [12] and Bandiya et al. [13] studies 2 to 3 doses of Surfaxin type of surfactant was given by BAL method.

\section{COMPLICATIONS}

As per the study between the groups (i.e. application of surfactant before and after $24 \mathrm{hrs}$.) the complications were $P P H N=5 / 20 \mathrm{v} / \mathrm{s} 2 / 10$, air leak $=1 \mathrm{v} / \mathrm{s}$ 1 , Pneumothorax $=1 \mathrm{v} / \mathrm{s} 0$, Emphysema $0 \mathrm{v} / \mathrm{s} 1$, none of them were statistically significant. Most studies conclude that there is no statistically significant decrease in the percentage of complications.

Outcome between the study groups -surfactant administration less than 24 hrs vs 25-48 hrs

\section{Duration of ventilation}

Mean duration of ventilation were $3.7 \mathrm{v} / \mathrm{s} 6.8$ days between the use of surfactant before and after 24 hrs. of birth with $\mathrm{P}$ value 0.026 which is statistically significant. Findlay et al. mentioned that the mean duration of ventilation decreased in the surfactant treated group but not otherwise specified [6].

\section{Duration of $\mathrm{O} 2$ requirement}

Mean duration of $\mathrm{O} 2$ requirement were 6.05 v/s 8.5 days between the use of surfactant before and after 24 hrs. of birth with $\mathrm{P}$ value 0.039 , which is statistically significant. Findlay et al also mentioned that the mean duration of $\mathrm{O} 2$ requirement decreased in the surfactant group but not otherwise specified [6].

\section{Primary Outcome}

Total no of deaths $=3 \mathrm{v} / \mathrm{s} 2[\mathrm{P}$ Value $=0.729]$, statistically not significant. Cochrane review mention that no significant statistical difference in the mortality was noticed among the groups in various case-control studies.

\section{CONCLUSION}

As per the present literature, surfactant is one of the recent advances in the therapy of MAS. The study was done with single dose bolus therapy of natural surfactant, administered to all those babies with Downe's score $>7$ which implies impending respiratory failure presenting within $48 \mathrm{hrs}$ of birth, with the exclusion criteria strictly applied. 
In our study, it is found that there was no statistically significant difference in mortality between those who received surfactant within $24 \mathrm{hrs}$ of birth and between $25-48$ hrs of birth, though the number is more in the former group.

Surfactant in a form of single bolus therapy within 24 hrs of birth has no role in decreasing the percentage of mortality in MAS in our study but however has shown benefit in terms of decreasing the mean duration of ventilation, $\mathrm{O}_{2}$ requirement and hospitalization thereby decreasing the cost of treatment as well as complications related to prolonged ventilation and hospitalization. Regarding complications surfactant administration didn't show statistically significant difference between those who received surfactant within $24 \mathrm{hrs}$ of birth and those who received between $25-48 \mathrm{hrs}$ of birth.

\section{REFFERENCE}

1. Ahlfeld, S.K. (2020). Meconium Aspiration. In Kliegman RM, St Geme III JW, Blum NJ, Shah SS, Tasker RC, Wilson KM, editors, Nelson Textbook of Pediatrics Vol 1; $21^{\text {st }}$ Edition Philadelphia: Elsevier;1095.

2. Wiswell, T. E., \& Bent, R. C. (1993). Meconium staining and the meconium aspiration syndrome: unresolved issues. Pediatric Clinics of North America, 40(5), 955-981.

3. Klingner, M. C., \& Kruse, J. (1999). Meconium aspiration syndrome: pathophysiology and prevention. The Journal of the American Board of Family Practice, 12(6), 450-466.

4. Lacaze-Masmonteil, T. (2007). Expanded use of surfactant therapy in newborns. Clinics in perinatology, 34(1), 179-189.

5. Shilpasri, Y.M., Madhurya, B. (2019). Clinical Study of Babies born through Meconium Stained Amniotic Fluid. Int J Contemp Pediatr, 6(2), 491496

6. El Shahed, A. I., Dargaville, P. A., Ohlsson, A., \& Soll, R. (2007). Surfactant for meconium aspiration syndrome in full term/near term infants. Cochrane Database of Systematic Reviews, (3).
7. Moya, F. R., Gadzinowski, J., Bancalari, E., Salinas, V., Kopelman, B., Bancalari, A., ... \& Tsai, H. (2005). A multicenter, randomized, masked, comparison trial of lucinactant, colfosceril palmitate, and beractant for the prevention of respiratory distress syndrome among very preterm infants. Pediatrics, 115(4), 10181029.

8. Auten, R. L., Notter, R. H., Kendig, J. W., Davis, J. M., \& Shapiro, D. L. (1991). Surfactant treatment of full-term newborns with respiratory failure. Pediatrics, 87(1), 101-107.

9. Halliday, H. L., Speer, C. P., \& Robertson, B. (1996). Treatment of severe meconium aspiration syndrome with porcine surfactant. European journal of pediatrics, 155(12), 1047-1051.

10. Findlay, R. D., Taeusch, H. W., \& Walther, F. J. (1996). Surfactant replacement therapy for meconium aspiration syndrome. Pediatrics, 97(1), 48-52.

11. Dargaville, P. A., \& Mills, J. F. (2005). Surfactant therapy for meconium aspiration syndrome. Drugs, 65(18), 2569-2591.

12. Wiswell, T. E., Knight, G. R., Finer, N. N., Donn, S. M., Desai, H., Walsh, W. F., ... \& Merritt, T. A. (2002). A multicenter, randomized, controlled trial comparing Surfaxin (Lucinactant) lavage with standard care for treatment of meconium aspiration syndrome. Pediatrics, 109(6), 1081 1087.

13. Bandiya, P., Nangia, S., \& Saili, A. (2018). Surfactant Lung Lavage vs. Standard Care in the Treatment of Meconium Aspiration Syndrome-A Randomized Trial. Journal of tropical pediatrics, 65(2), 114-121.

14. Lotze, A., Mitchell, B. R., Bulas, D. I., Zola, E. M., Shalwitz, R. A., Gunkel, J. H., \& Group, S. I. T. I. S. (1998). Multicenter study of surfactant (beractant) use in the treatment of term infants with severe respiratory failure. The Journal of pediatrics, 132(1), 40-47.

15. Maturana, A., Torres-Pereyra, J., Salinas, R., Astudillo, P., \& Moya, F. R. (2005). The Chile Surf Group. A randomized trial of natural surfactant for moderate to severe meconium aspiration syndrome. Pediatr Res, 57, 1545A. 